\title{
Childbearing depressive symptomatology in high-risk pregnancies: The roles of working models and social support
}

\author{
AVI BESSER,${ }^{a}$ BEATRIZ PRIEL,${ }^{b}$ AND ARNON WIZNITZER ${ }^{c}$ \\ ${ }^{a}$ Sapir Academic College; ${ }^{b}$ Department of Behavioral Sciences, Ben-Gurion University, Beer-Sheva, Israel; \\ and ${ }^{c}$ School of Medicine, Ben-Gurion University, Beer-Sheva, Israel
}

\begin{abstract}
Guided by both attachment and social support theories, the authors conducted a longitudinal investigation exploring the concomitant effects of perceptions of spouse support (anticipated and received spouse support) and internal working models of attachment (positive-self and positive-other), on childbearing depressive symptomatology. Distinct main and interaction effects for attachment dimensions and perceived support variables were hypothesized for high- and low-risk pregnancies. Participants in the final sample were 200 pregnant women who completed the self-report between the 25th and the 29th weeks of pregnancy, and 8 weeks after childbirth. Controlling for initial levels of depressive symptoms and health conditions, results demonstrated the protective role of high levels of received support and of positive-other models on childbirth depressive symptoms. Moreover, received support and models of positive-other were found to interact with health conditions, producing distinct moderation effects: Received support was found to be a significantly stronger protective factor for childbearing depression among women with low-risk pregnancies; positiveother models were found to be a significantly stronger protective factor among women with high-risk pregnancies. The implications of these findings for the understanding of intrapersonal and interpersonal factors in successful coping with a health risk situation are discussed.
\end{abstract}

Childbearing depression constitutes an important social and health problem (Hopkins, Marcus, \& Campbell, 1984; O’Hara, Schlechte, Lewis, \& Varner, 1991; Whiffen, 1992; Whiffen \& Gotlib, 1993). Even though a relatively low number of women are treated for severe childbearing depression, a large number of new mothers experience milder forms of dysphoria and feelings of inadequacy

We are very grateful to the Public Health Nursing Staff of the Israel Ministry of Health, Southern District, for their cooperation in making this research possible. This research was supported in part by the B. Steiner Family Center at Ben-Gurion University. We wish to thank the action editor and the anonymous reviewers for their very helpful comments on a draft of the article and the ideas involved.

Correspondence should be addressed to Avi Besser Sapir Academic College, D.N. Hot Ashkelon 79165, Israel. e-mail: besser@mail.sapir.il; or Beatriz Priel, Department of Behavioral Sciences, Ben-Gurion University, Beer-Sheva 84105, Israel. e-mail: bpriel@bgumail. bgu.ac.il.
(Gotlib, Whiffen, Mount, Milne, \& Cordy, 1989; Hopkins et al., 1984). Since most studies have identified depressive symptoms as present during pregnancy (Cutrona, 1984; Fleming, Ruble, Flett \& Wagner, 1990), Whiffen (1992) suggested the term childbearing depression to refer to different degrees of dysphoria that are prevalent during this process and may persist for up to one year (Terry, Mayocchi, \& Hynes, 1996). Childbearing depression has been found to have important implications for child development, affecting many aspects of the mother-child daily interaction that associate with infant behavior and cognitive processes (Murray, 1992; Murray, Fiori-Cowley, Hooper, \& Cooper, 1996).

Childbearing depressive symptomatology has been found to correlate with previous depression and psychiatric history (Whiffen \& Gotlieb, 1993), and with biological factors (Harris, 1993). Stress (O’Hara, Zekoski, Phillips 
\& Wright, 1990; Terry et al., 1996) and social support during pregnancy and immediately after childbirth (Collins, Dunkel-Schetter, Lobel, \& Scrimshaw, 1993; Cutrona, 1984; O’Hara, 1986) are probably the most extensively documented psychosocial factors correlated with depressive symptomatology after delivery. A related important factor is marital distress, which has been found to both increase stress and decrease available support in the childbearing period (Beach, Sandeen, \& O'Leary, 1990; O’Hara, 1986; Whiffen, 1988).

\section{Childbearing depressive symptomatology in high- and low-risk pregnancies}

Normal or low-risk pregnancies (LRP) correlate with moderate levels of stress, but pregnancies medically defined as "at high risk" (Pritchard \& MacDonald, 1980) may involve severe levels of health stress. Highrisk pregnancy (HRP) implies a significant possibility of fetal demise, life-threatening illness in the newborn, or serious health risk to the mother (Pritchard \& MacDonald, 1980). The medical risk that characterizes HRP is frequently assumed to jeopardize the completion of the mother's bonding to the fetus, affecting maternal coping capacities (Osofsky \& Osofsky, 1985) and increasing postpartum negative outcomes (Lobel, Dunkel-Schetter, \& Scrimshaw, 1992). Existent research indicates that the emotional reactions characteristic of normal pregnancies tend to be intensified or prolonged in high-risk pregnancies; studies show significantly higher levels of depressive symptomatology among HRP than among LRP women (Mercer \& Ferketich, 1988). In the present study, the high-risk pregnancy sample included women diagnosed with Type II gestational diabetes mellitus (GDM), that is, women who develop first-time diabetes during pregnancy. Women with GDM are expected to follow a specific eating plan and to test their blood glucose frequently, as well as take insulin (either injections or oral agents). These demands, in addition to the increased risk to the mother and fetus, considerably increase the stress of pregnancy, which may add to the risk of adverse birth outcomes (Rini, DunkelSchetter, Wadhwa, \& Sandman, 1999).

\section{Depression, attachment, and social support}

Reliance on others has been found to correlate with individuals' reactions to increased stress. Two main conceptual frameworks have focused on the study of individuals' reliance on others to meet basic needs: attachment and social support theories. Attachment theory assumes that, from the interpersonal experiences an individual has early in life, internal working models of self and others have an impact on the interpretation of, and reaction to, new relationships (Bowlby, 1969, 1973, 1980). The concept of internal working models of attachment was proposed as a cognitive and affective construct, including the subject's memories, perceptions, and expectations in relation to significant others. The attachment system was found to be most strongly activated under conditions of distress such as fatigue, illness, or fear (Bowlby, 1973, 1979).

A growing body of empirical research, based on Hazan and Shaver's (1987) pioneering work, has explored attachment patterns in adulthood and demonstrated an important association between attachment patterns and individuals' capacity to use significant others as sources of support and comfort (Simpson, Rholes, \& Nelligan, 1992). Bartholomew (1990) and Bartholomew and Horowitz (1991) proposed, on theoretical grounds, a classification of internal working models of attachment that is defined by the positivity of the models of self and the positivity of the models of others. The positivity of the self indicates the degree to which the self is lovable and worthy and others are expected to be responsive. The positivity of the other indicates a person's expectations about significant others' availability and expected support. These dimensions define four patterns of attachment (Griffin \& Bartholomew, 1994): secure (positive model of self and others), preoccupied (negative model of self and positive model of others), dismissing (positive model of self and negative model of others), and fearful (negative model of self and others).

Attachment theory has offered important insights for the understanding of depression. Bowlby extensively studied processes of depression and mourning, assuming that 
pathological mourning symptoms reflect a failure to internalize secure and positive patterns of attachment (Bowlby, 1980). Moreover, empirical research has shown that patterns of attachment affect depressive symptomatology in adult clinical and community samples (Carnelley, Pietromanco, \& Jaffe, 1994; Priel \& Shamai, 1995). Attachment research suggests that positive models of the other, but not of the self, are critical for individuals' perceptions of interpersonal relationships as supportive in stressful situations (Priel, Mitrani, \& Shahar, 1998). Moreover, basic definitions of patterns of attachment suggest that positive models of the other may constitute the main dimension involved in affect regulation in stressful situations. For instance, persons showing preoccupied attachment patterns (i.e., positive-other and negativeself models) are characteristically more able to use environmental resources than those with a predominant avoidant attachment style (i.e., positive-self and negative-other models); the latter are characterized by increased distancing when stress is heightened (Ainsworth, Blehar, Waters, \& Wall, 1978). Accordingly, in the present study, we expected the association between pregnancy risk status and childbearing depression to be moderated by positivity of the other.

Social support studies have centered on the role that resources provided by interpersonal relationships play in individuals' coping and adjustment (Wills, 1985). Cohen and Wills (1985) for instance, suggested that support from specific interpersonal relationships buffers the deleterious effects of stressful events. The idea that perceived interpersonal bonds play an important role in the regulation of distress is basic to conceptualizations of perceived social support in general (Priel \& Shamai, 1995; I. G. Sarason, Pierce, \& Sarason, 1990), and in relation to new mothers' adjustment in particular (Collins et al., 1993; Cutrona, 1984; O'Hara, 1986; Priel \& Besser, 2000a). Close social bonds, such as marriage, were found to be particularly beneficial (Cohen \& Wills, 1985) because significant others were assumed to provide emotional and instrumental help, thereby reducing negative outcomes (Barrera, 1986).
The study of social support in the childbearing period underlines the importance of the baby's father as the main source of support (Belsky \& Rovine, 1990; Collins et al., 1993; Coffman, Levitt, Deets, \& Quigley, 1991; Priel \& Besser, 2000a).

A considerable body of evidence (DunkelSchetter \& Bennett, 1990; B. R. Sarason et al., 1991) supports the important distinction between perceived social support (e.g., the expectation that social support will be available if needed) and received social support (e.g., reports of actually received support). Self-reports of social support may point to perceptions of anticipated social support and perceptions that social support has been received. In general, reports of anticipated support, but not of support actually received, have been found to predict positive outcomes and psychological and physical well-being (Cohen \& Wills, 1985; Hobfoll, Nadler, \& Lieberman, 1986; Peirce, Frone, Russell, Cooper, \& Muder, 2000). However, the role of social support mobilization and effectiveness is less clear in the case of severe stress or illness (Bolger, Foster, Vinokur, \& Ng, 1996). Although support from close relationships is generally an effective stress buffer in relation to moderately stressful life events (Cohen \& Wills, 1985), when stress is more severe, significant others might not be able to maintain their support (Gottlieb \& Wagner, 1991), may underestimate their partner's stress (Chapman, Hobfoll, \& Ritter, 1997), or may themselves be overwhelmed by the events (Coyne \& Fiske, 1992). These findings are coherent with the deterioration model of social support that has been proposed for very stressful situations (Kaniasty \& Norris, 1995). According to this model, higher levels of stress may change social support networks, thereby worsening outcomes. In the present study, we explored the moderating effects of perceptions of both anticipated and received social support in different health risk conditions, comparing the effects of social support on childbearing depression among HRP and LRP participants.

An association between internal working models of attachment and perceptions of social support from significant others has been 
suggested as a theoretical possibility (Hazan \& Shaver, 1987; B. R. Sarason, Sarason, \& Pierce, 1990; I. G. Sarason et al., 1990; I. G. Sarason, Sarason, \& Shearin, 1986; Wallace \& Vaux, 1993). B. R. Sarason et al.'s (1991) empirical study of the relation between perceived social support and the retrospective estimation of the quality of early parental care and overprotection reported moderate associations between perceptions of social support on the one hand, and working models of self and others on the other. These results confirmed the suggestion of I. G. Sarason et al. (1986) that the core idea in conceptualizations of both social support and secure attachment is rewarding ties with other people. Both concepts assume that individuals who feel more accepted and loved are less depressed and feel more capable. However, although assessments of social support center on the interpersonal aspect - mainly on the perception by individuals that others communicate their care (B. R. Sarason, Shearin, Pierce, \& Sarason, 1987)measures of attachment are assumed to tap the particular codes that guide a person's expectations and interpretations of relationships.

In the context of adult attachment theory, Simpson et al. (1992) reported distinctive styles of support-giving and support-seeking among securely and insecurely attached participants. These authors reported that, in a laboratory stress situation, securely attached participants tend to seek their partner's support and be helped by it significantly more than their avoidant or anxiously attached counterparts. Their study offered empirical evidence on the relations between attachment styles and actual behavior in an adult population. Wallace and Vaux (1993) reported that the social support network orientation predicts adult attachment style: Secure subjects were found to be more positively oriented toward their support networks than insecurely attached subjects. Avoidantly attached subjects showed a more independent network orientation than ambivalent (preoccupied) individuals.

Existing research suggests that attachment and social support constructs share the assumption that basic personal characteristics influence expectations, interpretations, and actual patterns of interpersonal behavior. We note, however, that although social support is defined as an interpersonal variable, its internal working models are a cognitive-affective, intrapersonal, personality dimension. Accordingly, studies of social support center more on contextual dimensions than on the history of relationships, but the opposite may be more accurate about attachment theory. These differences of emphasis are relative, however, since conceptualizations of social support as a multidimensional construct underscore ties with other people in the past as well as in the present (I. G. Sarason et al., 1986).

\section{The present study aims and leading hypotheses}

A main aim of the present study was to explore the concomitant effects of spouse support and attachment models on childbearing depressive symptomatology in women with high- and low-risk pregnancies. Although attachment and social support are related concepts with important common tenets, empirical evidence points to a possible difference: In cases of severe stress or health risk, there is evidence that the moderating effects of social support may be weakened (Bolger et al., 1996; Gottlieb \& Wagner, 1991); and according to the basic tenets of attachment theory, internal working models refer to the expectations a person has about the availability and responsivity of significant others, mainly in distressful situations (Bowlby, 1969). These findings suggest that, in the case of childbearing depressive symptomatology, social support may be a better moderator of distress in normal health conditions. Thus, the buffering effect of social support was expected in low-risk pregnancies, and we assumed that positive models of attachment, less likely to be affected by external conditions, would exert a protective effect among high-risk participants.

We explored the effects of interactions between pregnancy risk and perceptions of social support or dimensions of attachment on depressive symptoms after delivery, using a longitudinal design. This design was aimed at controlling for initial levels of depressive symptomatology, allowing also for the 
assessment of predelivery participants' reports of anticipated husband support (perceived anticipated support) and their report of actual support from husband after the delivery (perceived actual support). Repeated measures of social support also allowed us to control for possible associations between Time 1 measures of support, attachment, and depression. To ease reading we shall refer to these two kinds of perceptions of support as anticipated and received support.

To sum up, the following main hypotheses were investigated in the context of childbearing depressive symptomatology:

H1: More-positive models of the other and higher levels of anticipated and received support would be expected to predict lower levels of childbearing depressive symptomatology.

H2: The combination of high positive models of self and of other (i.e., secure attachment) would be correlated with the lowest levels of childbearing depressive symptomatology.

H3: Perceptions of social support may moderate ${ }^{l}$ depressive symptoms, mainly in the absence of health risk, and assessments of attachment may moderate depressive symptomatology, mainly in health risk situations.

\section{Method}

\section{Participants}

We approached 262 pregnant women, including 116 women with low-risk pregnancies and 146 women with Type II GDM and therefore classified as having high-risk pregnancies. Participants were Israeli, White, Jewish, married women, without previous history of diabetes or other mental or physical illness. Our sample included only women born in

1. In line with Baron and Kenny (1986), we use the term moderator to refer to variable that qualifies the effect of a predictor $(X)$ variable on a criterion variable $(Y)$.
Israel, excluding immigrant pregnant women. Forty-seven percent of the participants were of North African descent. Ten well-baby clinics serving urban lower- and middle-class neighborhoods participated in this study. All participants had been routinely administered a $50-\mathrm{g}$ oral glucose load at 24-28 weeks of gestation. Women having normal fasting values and two abnormal glucose tolerance tests (at 1 and 3 hours) had been designated as having GDM high-risk pregnancies (O'Sullivan \& Mahan, 1964) and had been transferred to the HighRisk Gynecology Unit for follow-up examinations (this unit is part of a very modern, up-todate hospital service). The LRP women continued to attend the community well-baby clinic for routine pregnancy follow-up. Of the 116 LRP and 146 HRP women we first contacted, 103 LRP (89\%) and 110 HRP (75\%) agreed to take part in this study. The final sample included only those who subsequently had normal childbirth and healthy babies. Infants' health status was defined according to Apgar scores of 8 and higher as a criterion for normality in newborns (W. E. Nelson, 1987). Ten participants were excluded from the HRP because they had miscarriages $(n=5)$, delivered prematurely $(n=3)$, refused to take part at Time 2 data collection $(n=1)$, or the baby had an abnormal Apgar score $(n=1)$. Among the LRP participants three were excluded: 2 delivered prematurely and 1 participant moved out of the area before Time 2 data collection. Thus, our final sample included $100 \mathrm{HRP}$ and $100 \mathrm{LRP}$ participants. Mean age was 27.54, $S D=4.84$. All participants were delivered in the same modern regional hospital and were released after two regular days of hospitalization.

Participants had 10-20 years of formal education with Mean $=12.21, S D=1.76$ (see Table 1, in the Results section). ANOVAs were run on demographic and Time 1 variables assessments, comparing our sample to the 13 participants who were dropped; differences were nonsignificant.

\section{Measures}

Relationship questionnaire. The Relationship Questionnaire (RQ) developed by 
Bartholomew \& Horowitz (1991) was used to assess adult models of attachment. The RQ consists of four short paragraphs, each describing a prototypical attachment pattern (i.e., secure, preoccupied, fearful-avoidant, and dismissing-avoidant). Participants were asked to select the paragraph that described them most accurately (categorical attachment classification), and then to evaluate on a 5-point scale the extent to which each of the four paragraphs represented them (continuous attachment classification). Cronbach alpha internal consistency coefficients were .92 and .90 for LRP and HRP, respectively.

The construct validity of this measure has been demonstrated (Griffin \& Bartholomew, 1994). Following the recommendations in the attachment literature on the relevance of continuous over categorical measures of adult attachment (Griffin \& Bartholomew, 1994), in the present study we used assessments of the positivity of self and positivity of other as the two main continuous attachment dimensions. Assessments of the positivity of self dimension were obtained by summing the scores of the two attachment patterns with positive models of the self (secure and dismissing) and subtracting the scores of the two attachment patterns with negative models of the self (preoccupied and fearful). The positivity of other dimension was computed by summing the scores of the two attachment patterns with positive models of the other (secure and preoccupied) and subtracting the scores of the two attachment patterns with negative models of the other (dismissing and fearful)

Perceived spouse support. The Support Expectations Index (SEI), developed by Levitt, Coffman, Guacci-Franco, and Loveless (1994) for the study of the childbirth period's specific support needs and experiences, was used to assess social support. This is a 14-item questionnaire that assesses the extent to which the mother-to-be expects a specific close relation to provide emotional and instrumental support after the baby is born. At Time 1, we assessed participants' expectations of husband support after delivery (anticipated support). At Time 2 we modified these instructions, asking participants about the extent to which each support item was perceived as being provided by the husband (received support). Higher scores indicated perceptions of greater spouse support, as assessed before delivery (Time 1) and after delivery (Time 2). These two assessments will be referred to as anticipated support and received support, respectively. Cronbach alpha internal consistency coefficients for anticipated support for LRP and HRP were .89 and .86 , respectively; for received support the Cronbach coefficients were .87 and .88 for LRP and HRP, respectively.

\section{The Center for Epidemiological Depression} scale (CES-D). The CES-D was used to measure depressive symptoms during pregnancy and 8 weeks after delivery. This 20 -item scale was designed to measure current levels of depressive symptomatology in the general population. Items, assessed on a scale from 0 to 3 , are depressed mood, feelings of guilt and worthless, feelings of helplessness and hopelessness, psychomotor retardation, loss of appetite, and sleep disturbances (Radloff, 1977). This scale has been shown to be valid and reliable in many different samples, including pregnancy and postpartum research (see, e.g., Fleming et al., 1990; Priel and Besser, 1999; Priel and Besser, 2000a). Cronbach alpha values for CES-D 1 were .87 for LRP and .85 for HRP. CES-D 2 Cronbach's alpha values were .86 and .88 for LRP and HRP, respectively.

\section{Procedure}

Participants were asked to volunteer for a study on women's experiences of pregnancy and motherhood. Data were collected during the participants' checkups and all participants were interviewed during their routine follow-up examinations (LRP women were seen at the well-baby clinics, and HRP participants were interviewed at the High Risk Gynecology Unit).

Two waves of measurement were performed. Participants fulfilled the demographic and clinical criteria and completed the selfreport between the 25th and the 29th weeks of pregnancy (Time 1) and 8 weeks after childbirth (Time 2). 
At Time 1, participants completed the CES-D, the RQ, and the pregnancy form of the SEI. Time 2 assessments included the CES-D and the postpartum version of the SEI. The order of presentation of the questionnaires was randomized. Depression assessments before and after giving birth are referred to as CES-D 1 and CES-D 2, respectively.

\section{Results}

\section{Descriptive statistics}

Differences between the LRP and HRP were tested using a MANOVA with risk group as the independent variable and all variables in the study as the dependent variables. Table 1 presents the means, $S D$ s, and univariate $F \mathrm{~s}$ of this analysis.

Education levels among HRP and LRP women were found to be similar, but HRP women were significantly older than their LRP counterparts. We therefore controlled for age in subsequent analyses.

CES-D means scores at Times 1 and 2 were not significantly different among the LRP participants $(t[99]=-1.27, p=.21)$, but Time 2 assessments of depression were significantly higher among the HRP participants $(t[99]=$ $-4.13, p=.000)$. As can be seen in Table 1, CES-D 1 scores among LRP and HRP did not differ significantly, but we did find significant differences between their CES-D 2 scores. This pattern of findings points to an important increase of depressive symptomatology after delivery among HRP women only.

In our sample, $34 \%$ of the LRP and $28 \%$ of the HRP women during pregnancy and $38 \%$ of the LRP and $46 \%$ of the HRP women as new mothers scored above 16 on this scale, the cutoff point for depression symptomatology in community samples. Correlations between CES-D 1 and CES-D 2 scores were $.43, p<.0001$, and $.36, p<.0001$, among HRP and LRP participants, respectively (see Table 3, later), indicating a moderately consistent level of depressive symptoms during pregnancy and after delivery.

No significant differences were found when comparing social support scores among HRP and LRP women. The two samples were similar also in relation to the positive-other dimension

Table 1. Group differences for the study variables

\begin{tabular}{|c|c|c|c|}
\hline Variables & $\operatorname{LRP}(N=100)$ & $\operatorname{HRP}(N=100)$ & $F(1,198)$ \\
\hline \multicolumn{4}{|l|}{ Demographic } \\
\hline Age & $25.19(3.27)$ & $29.88(5.02)$ & $61.24 * * *$ \\
\hline Education & $13.07(1.61)$ & $13.35(1.89)$ & $1.27 \mathrm{~ns}$ \\
\hline \multicolumn{4}{|l|}{ Spouse support } \\
\hline Anticipated support & $84.21(12.04)$ & $83.83(12.92)$ & $.04 \mathrm{~ns}$ \\
\hline Received support & $83.90(13.99)$ & $80.69(16.54)$ & $2.20 \mathrm{~ns}$ \\
\hline \multicolumn{4}{|l|}{ Attachment dimensions } \\
\hline Positive self ${ }^{\mathrm{a}}$ & $2.15(2.027)$ & $.43(2.73)$ & $25.52 * * *$ \\
\hline Positive other ${ }^{b}$ & $.83(2.15)$ & $.77(3.15)$ & $.02 \mathrm{~ns}$ \\
\hline \multicolumn{4}{|c|}{ Depressive symptomatology ${ }^{\mathrm{c}}$} \\
\hline CES-D 1 & $12.61(6.11)$ & $12.32(7.22)$ & $.09 \mathrm{~ns}$ \\
\hline CES-D 2 & $13.54(6.79)$ & $15.61(7.71)$ & $4.06 *$ \\
\hline
\end{tabular}

Note. Standard deviations are in parentheses. $L R P=$ low risk pregnancy; $H R P=$ high risk pregnancy.

$* p<.05 . * * p<.01 . * * * p<.001$ (two-tailed tests).

${ }^{\mathrm{a}}$ Positive self $=($ Secure + Dismissed $)-($ Fearful + Preoccupied $)$.

${ }^{\mathrm{b}}$ Positive other $=($ Secure + Preoccupied $)-($ Dismissed + Fearful $)$.

${ }^{\mathrm{c}}$ CES-D 1 = depression measured at Time 1; CES-D 2 = depression measured at Time 2. 
Table 2. Attachment styles' distributions among high-and low-risk pregnancies

\begin{tabular}{lcccc}
\hline \hline Attachment style & Secure & Fearful & Preoccupied & Dismissing \\
\hline Risk group & & & & \\
LRP $(n=100)$ & $45 \%$ & $22 \%$ & $15 \%$ & $18 \%$ \\
HRP $(n=100)$ & $46 \%$ & $20 \%$ & $20 \%$ & $14 \%$ \\
Sample as a whole $(N=200)$ & $91(45.5 \%)$ & $42(21 \%)$ & $35(17.5 \%)$ & $32(16 \%)$ \\
\hline \hline
\end{tabular}

Note: $L R P=$ low risk pregnancy; $H R P=$ high risk pregnancy.

of attachment, but differed on the positive-self dimension, with significantly higher scores on this latter variable in the LRP group (Table 1). The LRP and HRP distribution of attachment styles (see Table 2 ) did not differ significantly $\left(\chi^{2}[d f=3]=1.32, p=.72\right)$.

In their original sample, Bartholomew and Horowitz (1991) reported percentage distributions of 47, 21, 18, and 14 for secure, fearful, preoccupied, and dismissing participants, respectively. In our previous studies with LRP pregnant women, the percentage distributions of attachment styles was 45.22, 20.87, 10.43, and 23.48 (Priel \& Besser, 2000b) and 45.83, 20.83, 10.83, and 22.50 (Priel \& Besser, 2001) for secure, fearful, preoccupied, and dismissing participants, respectively. None of the differences between the proportions of individuals in each attachment style group for the four independent samples was statistically significant.

Table 3 presents the correlations between demographic variables, attachment dimensions, social support scales, and assessments of depressive symptoms before and after giving birth. For the HRP sample, we found a significant association between participants' ages and their scores in the positive-other and anticipated support variables, with younger subjects reporting more positive models of the other and higher levels of anticipated support. In both samples, correlations between assessments of depressive symptomatology (CES-D 1 and CES-D 2), between anticipated and received support, and between positive self and positive other are moderate (.38 to .57).

As can be seen in Table 3, we found moderate to high correlations between assessments of attachment and received support in the LRP group; these correlations were non- significant in the HRP group, excluding the positive correlation between anticipated support and positivity of self. In the LRP sample, the received support variable and the two attachment dimensions (positive other and positive self) were found to correlate significantly with CES-D 2 in the expected direction: More positive models of self and other and greater social support were correlated with less depressive symptomatology after delivery. We found moderately strong associations between attachment dimensions and received social support, and moderate correlations between the two dimensions of attachment and anticipated social support: Participants scoring higher on the positive self and positive other anticipated and received more support from their husbands after delivery (see Table 3).

\section{The moderating role of anticipated spouse} support and attachment dimensions: Analytic strategy ${ }^{2}$

To examine the moderating roles of social support and attachment dimensions on the relationships between pregnancy risk and childbearing depression, we computed a twostage hierarchical multiple regression with interaction terms (Cohen \& Cohen, 1983).

In the first stage, two separated regressions were performed: one for the prediction of

2. All the analyses described, reported, and presented in the study are using the CES-D in the formal and standard way of total scores (Radloff, 1977). However, analyses were conducted also excluding the somatic items from CES-D scale, thus eliminating a possible confounding with the physical effects of pregnancy. Analyses with and without somatic items produced very similar results (data not shown here). 
Table 3. Correlations between the study variables

\begin{tabular}{crrrrrrr}
\hline \hline Variables & 1 & 2 & 3 & 4 & 5 & 6 & 7 \\
\hline 1. Age & - & -.02 & -.17 & .10 & .10 & .01 & -.13
\end{tabular}

Attachment dimensions
2. Positive self ${ }^{\mathrm{a}} \quad-.07$
3. Positive other ${ }^{\mathrm{b}}$
$-.24 *$
$\begin{array}{lll}- & .57 * * * & -.00 \\ .40 * * * & - & -.02\end{array}$
$\begin{array}{ll}-.28 * * & .34 * * * \\ -.22 * & .36 * * *\end{array}$
$.60 * * *$
$.67 * * *$

Depressive symptomatology ${ }^{\mathrm{c}}$
4. CES-D 1
5. CES-D 2
$-.16$
$-.19-.15$
-
$.36 * * * \quad .07$
$-.10$
$-.36^{* *}-.38^{* * *}$
$.43 * * *-11$
$-.47 * * *$

Spouse support
6. Anticipated support $-.34 * * *$
$.22 *$
.13
.06
.05
$-.27 * *$
-
$.40 * * *$
7. Received support $\quad-.15$
$.10-.16$
$-.23 *$
$.38 * * *$

Note. Low-risk pregnancy $(N=100)$ correlations are indicated above the diagonal; high-risk pregnancy $(N=100)$ correlations are indicated below the diagonal.

${ }^{*} p<.05 . * * p<.01 . * * *<<.001$ (two-tailed tests).

${ }^{\text {a}}$ Positive self $=($ Secure + Dismissed $)-($ Fearful + Preoccupied $)$.

${ }^{\mathrm{b}}$ Positive other $=($ Secure + Preoccupied $)-($ Dismissed + Fearful $)$.

${ }^{\mathrm{c}}$ CES-D 1 = depression measured at Time 1; CES-D 2 = depression measured at Time 2.

anticipated and received support, and the second for the prediction of positive-self and positive-other attachment dimensions. In the second stage, we combined these two models into one regression model. This combined regression accounts for predictors' overlap, as well as for their combined associations with the outcome, thus eliminating Type I errors known to result from multiple separate analyses (Gunster, Fusilier, and Mayes, 1986). Accordingly, only the significant interactions obtained in both stages were interpreted.

In each of these three regression models, the first three steps were identical. The risk group dichotomous dummy variable was entered in Step 1, explaining $2 \%$ of the variance of depressive symptoms. The addition of participants' ages in Step 2 did not add significantly to the prediction of Time 2 depressive symptomatology. In order to control for the participants' baseline levels of depression, we entered CES-D 1 scores in Step 3, thereby eliminating confounding effects when interpreting significant associations between predictors and criterion. CES-D 1 added $17 \%$ to the explained variance of CES-D 2. Subsequently we computed the three regressions.
R1. The moderating role of perceived spouse support. To study the moderating role of perceived spouse support (see part R1 of Table 4), we entered in Step 4 the anticipated and received spouse support assessments, adding a significant $8 \%$ to the explanation of the variance of Time 2 depressive symptoms; higher levels of received, but not anticipated, support correlated significantly with lower CES-D 2 scores. In Step 5 the interaction between anticipated and received support did not add to the prediction. In the final step (Step 6), the Risk $\times$ Anticipated Support and Risk $\times$ Received Support interactions were entered, adding a significant $4 \%$ to the explanation of the variance of Time 2 depressive symptoms. Both interactions were found to be significant and the complete regression model analyzed, explaining $32 \%$ of the variance of depressive symptomatology at Time 2.

R2. The moderating role of attachment dimensions. To investigate the moderating role of attachment dimensions (see part R2 in Table 4), we entered in Step 4 of a second regression the positive-self and positive-other dimensions of attachment that explained an 
Table 4. Multiple regression analyses of Time 2 depressive symptomatology separated for support and attachment models

\begin{tabular}{llllllll}
\hline \hline Predictor variables & Multiple $R$ & $R^{2}$ & $\Delta R^{2}$ & $F$ Change & Overall $F$ & $d f$ & $\beta$ \\
\hline
\end{tabular}

R1. Spouse support

Step 1

1. Risk group ${ }^{\mathrm{a}, \mathrm{b}}$

Step 2

2. Age

Step 3

3. Time 1 depressive symptomatology

Step 4

4. Time 1 anticipated spouse support

5. Time 2 received spouse support

Step 5

6 . Received $\times$ Anticipated spouse support

Step 6

7. Anticipated spouse support $\times$ Risk group

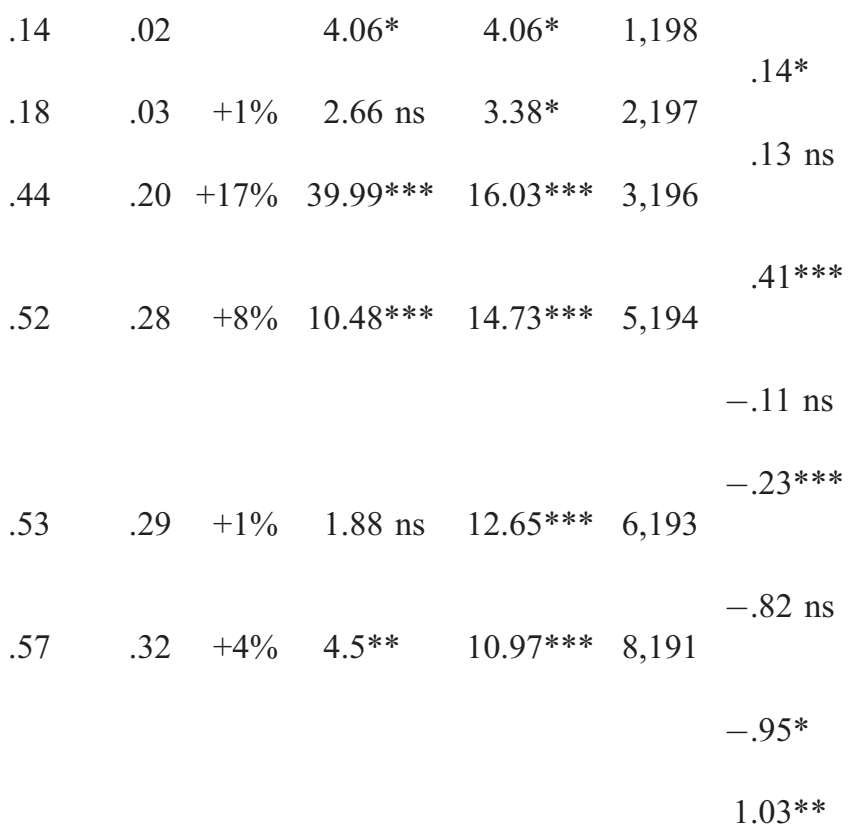

8. Received spouse support $\times$ Risk group

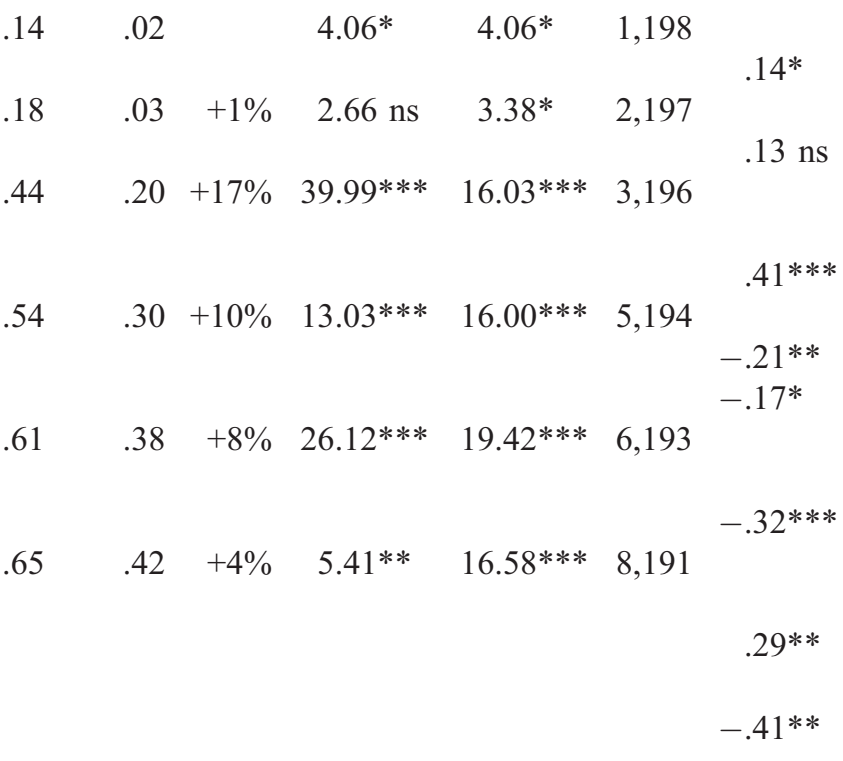

R2. Attachment models

Step 1

1. Risk group ${ }^{\mathrm{a}, \mathrm{b}}$

Step 2

2. Age

Step 3

3. Time 1 depressive symptomatology

Step 4

4. Positive self ${ }^{\mathrm{c}}$

5. Positive other ${ }^{\mathrm{d}}$

Step 5

6. Positive self $\times$ Positive other

Step 6

7. Positive self $\times$ Risk group

8. Positive other $\times$ Risk group

Note: $N=200$.

${ }^{*} p<.05 .{ }^{* *} p<.01 .{ }^{* * *} p<.001$ (two-tailed test).

${ }^{a}$ High-risk pregnancy $(n=100)$.

${ }^{\mathrm{b}}$ Low-risk pregnancy $(n=100)$.

${ }^{c}$ Positive self $=($ Secure + Dismissed $)-($ Fearful + Preoccupied $)$.

${ }^{\mathrm{d}}$ Positive other $=($ Secure + Preoccupied $)-($ Dismissed + Fearful $)$. 
additional significant $10 \%$ of the variance of CES-D 2; higher positive self and positive other correlated with lower CES-D 2 scores. In Step 5 the Positive Self $\times$ Positive Other interaction added a significant $8 \%$ to the prediction. In the final step (Step 6), the risk group interactions with positive self and positive other were entered, explaining an additional significant $4 \%$ of the variance of Time 2 depressive symptoms. Both interactions were found to be significant and the complete regression model analyzed, and explained $42 \%$ of the variance of depressive symptomatology at Time 2 .

R3. The combined regression. To examine the moderating roles of social support and attachment dimensions on the relationships between pregnancy risk and childbearing depression, we computed a combined hierarchical multiple regression with interaction terms (Cohen \& Cohen, 1983); see Table 5. Significant interaction effects in the combined model that had also reached significance in the separate analyses reported above were considered as stable effects, and were interpreted. Any interaction found in the combined model that was nonsignificant in the previous separate models might plausibly be attributed to multicollinearity and models' overloading, and may thus be considered spurious. As in the separated analyses, in this combined analysis we entered the risk group dichotomous dummy variable, and the participants' ages and baseline levels of depression in Steps 1, 2, and 3 respectively.

In Step 4, we entered anticipated and received spouse support assessments, adding a significant $8 \%$ to the explanation of the variance of Time 2 depressive symptoms; the higher levels of received, but not anticipated, support correlated significantly with lower CES-D 2 scores. The positive-self and positive-other dimensions of attachment were entered in Step 5, adding a significant 5\% to the variance explanation; higher positive self and positive other correlated with lower CES-D 2 scores. In Step 6, we entered the Positive Self $\times$ Positive Other and the Anticipated Support $\times$ Received Support interactions, adding 7\% to the explained variance of CES-D 2. The
Positive Self $\times$ Positive Other interaction was found to be significant (see Figure 1). This step was also aimed at eliminating possible confounding effects when interpreting significant interactions in the next step.

As can be seen in Figure 1, in addition to risk groups and initial levels of depression, the levels of positive other determine the correlation between positive self and childbearing depression. Positive-self scores predicted high childbearing depression when positive-other scores were low. However, a high positive other attachment dimension moderated this effect. The combination of high positive-self and positive-other scores (i.e., secure attachment) was found to associate with the lowest level of childbearing depressive symptomatology. The combination of high positive-self scores and low positive-other scores (i.e., dismissing attachment) was found to be associated with the highest level of childbearing depressive symptomatology.

In Step 7, we entered the risk group interactions with support assessments and with attachment dimensions. This step added a significant $9 \%$ to the explanation of the variance of CES-D 2. The Risk Group $\times$ Positive Other and the Risk Group $\times$ Received Spouse support interactions were significant. These interactions are presented in Figures 2 and 3 , respectively.

As can be seen in Figure 2, the moderating effects of the positive-other scores are significantly stronger among HRP participants. HRP women scoring high on the positiveother dimension are significantly less depressed than HRP women who scored low on the positive-other dimension. Positive-other scores showed the expected negative relation to childbearing depression for LRP women too, but this relation was not as strong as it was for HRP women.

As can be seen in Figure 3, beyond the risk groups and initial levels of depression, participants low in received support were more depressed than those reporting high received support; however, the difference in depressive symptomatology between participants low and high in received support is significantly greater among the LRP. These findings indicate that the moderating effects of received 
Table 5. Multiple regression analysis of Time 2 depressive symptomatology combined for support and attachment models to test overlap

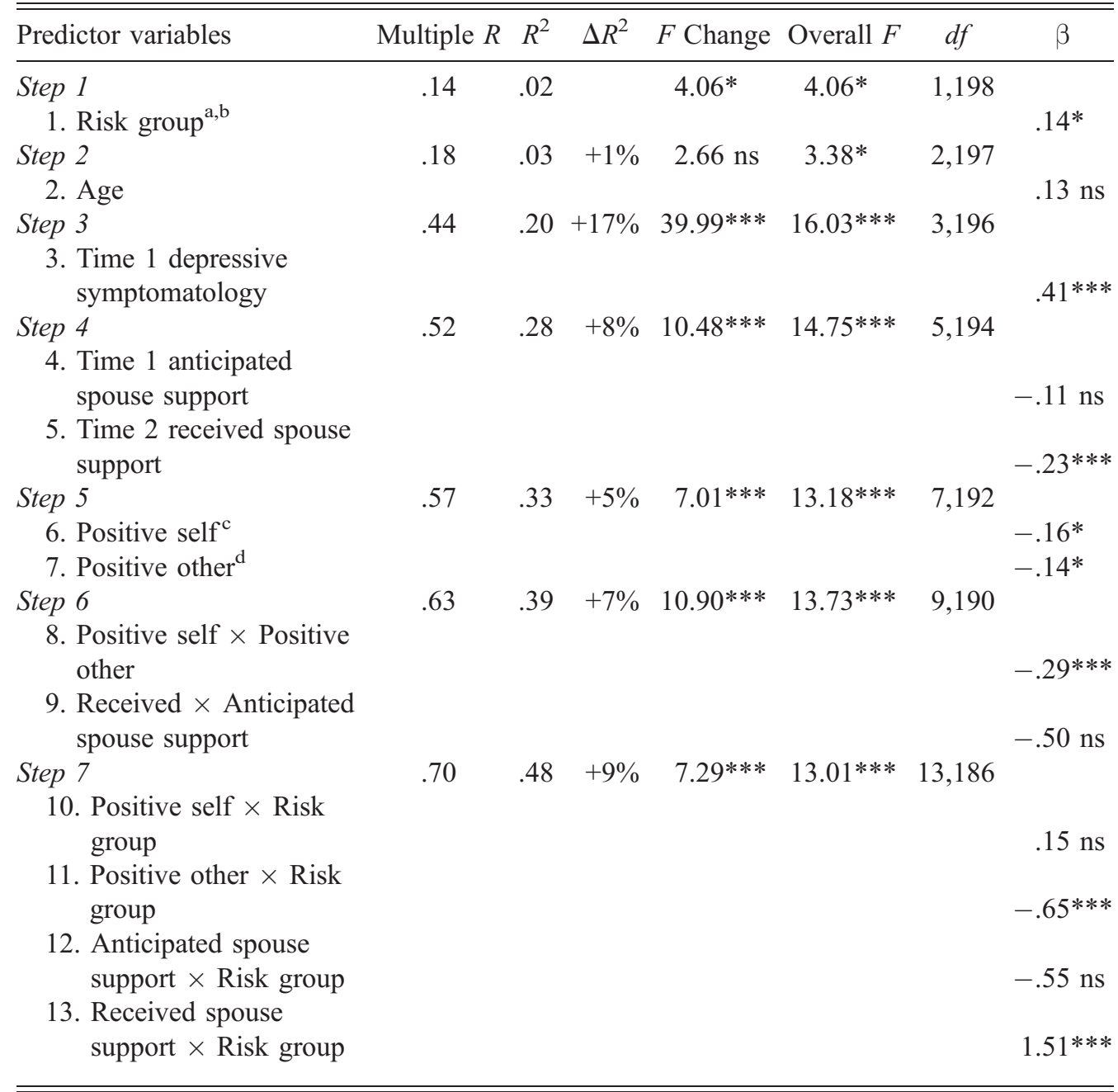

Note: $N=200$.

${ }^{*} p<.05 .{ }^{* *} p<.01 .{ }^{* * *} p<.001$ (two-tailed test).

${ }^{\text {a }}$ High risk pregnancy $(n=100)$.

${ }^{\mathrm{b}}$ Low risk pregnancy $(n=100)$.

${ }^{\mathrm{c}}$ Positive self $=($ Secure + Dismissed $)-($ Fearful + Preoccupied $)$.

${ }^{\mathrm{d}}$ Positive other $=($ Secure + Preoccupied $)-($ Dismissed + Fearful $)$.

support on childbearing depressive symptomatology are significantly stronger in the LRP group. Received support showed the expected negative relation to childbearing depression for HRP women, but this relation was not as strong as it was for LRP women.

The complete regression model analyzed explained $48 \%$ of the variance of depressive symptomatology at Time 2 . Beyond the effects of depressive symptoms during pregnancy and participants' age differences, the attachment and social support variables added $29 \%$ to the explanation of the variance of childbearing depressive symptomatology. Three- and fourway interactions did not add significantly to the explanation of CES-D 2 variance and are therefore not shown in Table 5.

A comparison of the results obtained using the separate and combined analytic strategies strengthens the Received Support $\times$ Risk 


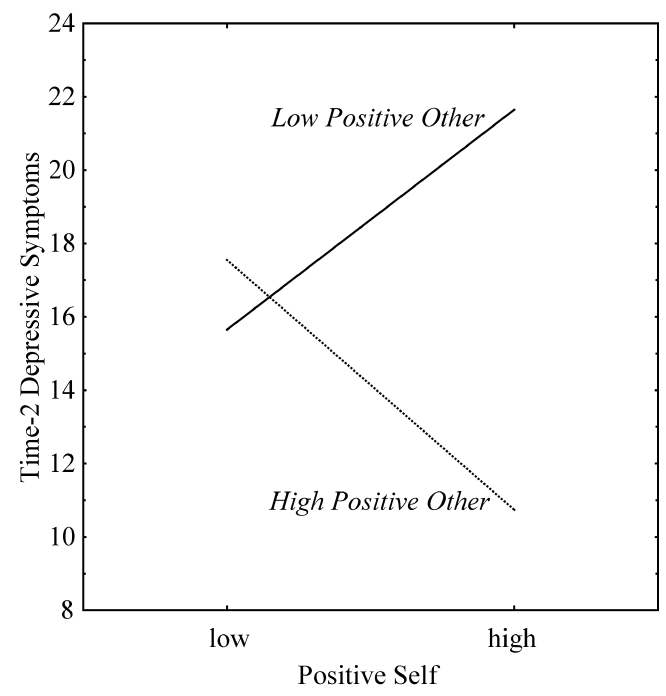

Figure 1. Relations between high (1 SD) and low $(-1 S D)$ levels of positive self and childbearing depressive symptomatology for high $(1 S D)$ and low $(-1 S D)$ levels of positive other. [Interactions were plotted according to Cohen and Cohen's (1983, p. 323 and p. 419) recommendation.]

Group and the Positive Other $\times$ Risk Group significant moderation effects revealed in the combined model. However, the Anticipated Support $\times$ Risk Group and Positive Self $\times$ Risk Group significant effects revealed in the separated models' analyses are not reiterated when using a combined analysis, most probably indicating that these effects are not stable enough.

Four additional post hoc hierarchical multiple regression analyses were performed on the final model in order to explore the relative contribution of each of the support and attachment variables. We computed again the regression presented in Table 5, but in Step 4, we entered the anticipated and received support variables, one per equation. Anticipated support added $4 \%$ to the explained variance in CES-D 2 scores $(F[4,195]=$ $14.90, p<.0000, F$ change $=9.43, \beta=-.20$, $p<.002)$. We then entered the received support scores that added $7 \%(F[4,195]=$ $17.59, p<.0000, F$ change $=18.09, \beta=-.27$, $p<.0000)$ to the explanation of CES-D 2 variance. In Step 5 of this regression, we entered the two attachment measures, one per equation; positive self added $4 \%(F[6,193]=$ $14.52, p<.0000, F$ change $=9.99, \beta=-.22$, $p<.002)$ to the explanation of CES-D 2 variance. We then entered the positive-other variable, adding $3 \%(F[6,193]=14.35$, $p<.0000, F$ change $=9.27, \beta=-.18, p<.01)$ to the explanation of CES-D 2 variance.

In order to explore the contribution of support assessments while controlling for the attachment dimensions, we reversed the order of Steps 4 and 5. We entered attachment measures in Step 4, adding $10 \%$ to the explanation of CES-D 2 variance $(F[5,194]=$ $14.35, p<.0000, F$ change $=13.03, p<.000$, $\beta=-.21, p<.004$ and $\beta=-.17, p<.02$ for positive self and positive other, respectively). When anticipated and received support were entered in Step 5, they added 3\% to the prediction of CES-D $2(F[7,192]=13.18$, $p<.0000, F$ change $=4.63, p<.01, \beta=-.08$, $n s$ and $\beta=-.16, p<.02$ for anticipated and received support, respectively).

These last analyses demonstrate that social support and attachment variables are related but independent constructs, and that each of them makes a specific contribution to the

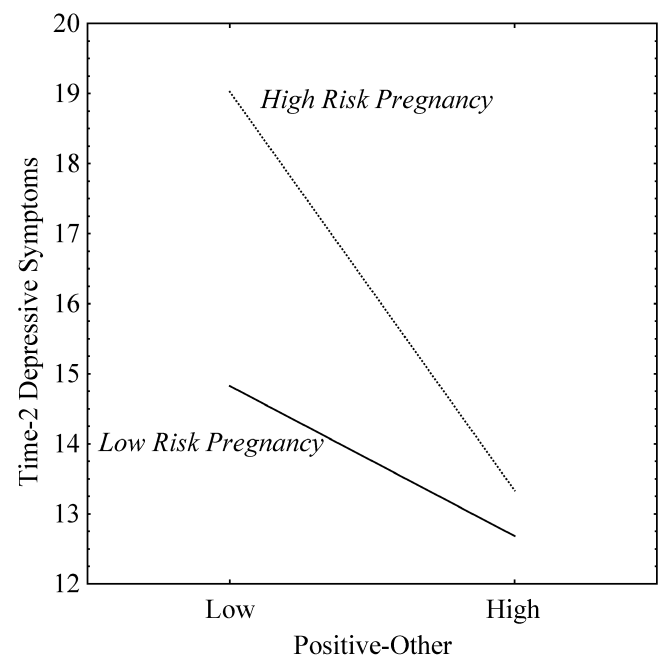

Figure 2. Relations between risk group and childbearing depressive symptomatology for high $(1 S D)$ and low $(-1 S D)$ levels of positive other. [Interactions were plotted according to Cohen and Cohen's (1983, p. 323 and p. 419) recommendation.] 


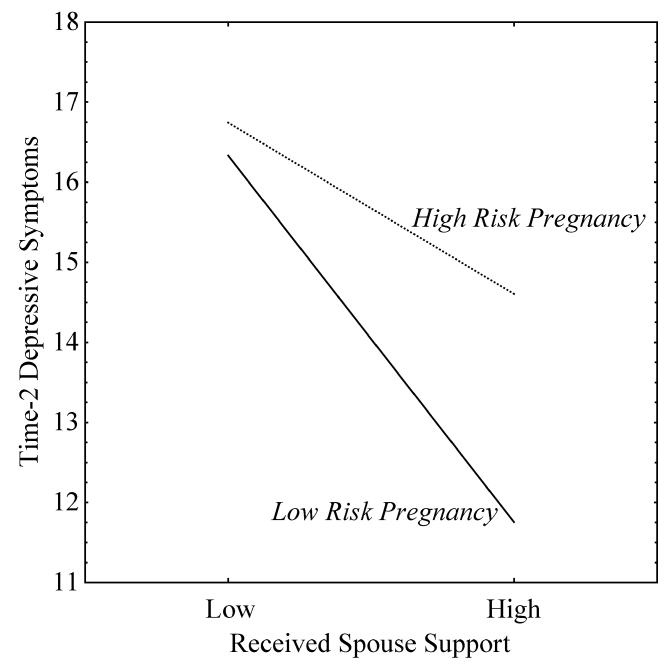

Figure 3. Relations between risk group and childbearing depressive symptomatology for high (1 $S D)$ and low (-1 SD) levels of received support. [Interactions were plotted according to Cohen and Cohen's (1983, p. 323 and p. 419) recommendation.]

explanation of the variance of childbearing depressive symptomatology, after controlling for risk group, age, and CES-D 1.

\section{Discussion}

The present study results underscore a conceptualization of attachment and social support as related but distinct constructs. Both attachment and social support variables were found to reduce childbearing depressive symptoms. The extent of this effect, however, was found to vary according to the pregnancy risk conditions: Although increased health risk had a deleterious effect on all participants, those with more positive models of attachment were found to be significantly more resilient when health risk was high. Received support was found to reduce significantly depressive symptomatology in low health risk conditions.

\section{High-risk pregnancies and depressive symptomatology}

HRP and LRP participants presented similar depressive symptomatology scores during pregnancy, but HRP women were significantly more depressed after childbirth. In interpreting these findings, it has to be taken into account that, in the sample selected, all the HRP pregnancies ended well for the mother and the baby; therefore differences in CES-D 2 cannot be attributed to mother or child health problems after birth. One might expect that HRP women whose pregnancies finished well would be relieved and less depressed, but our results are congruent with previous empirical findings on the association between HRP and higher levels of depressive symptoms after childbirth (Lobel et al., 1992; Mercer \& Ferketich, 1988). A plausible explanation to these nonintuitive results is the postponement of maternal bonding to the newborn infant found among mothers after HRP, due to the uncertainty that characterizes these pregnancies (Priel \& Besser, 1999; Priel \& Kantor, 1988). Moreover, maternal attachment to the fetus and the newborn has been found to constitute a main moderator of health-related coping behaviors (L. J. Nelson \& Fazio, 1995) and childbearing depressive symptoms (Priel \& Besser, 1999).

\section{High-risk pregnancy and social support}

HRP and LRP samples did not differ in the amount of anticipated or received spousal support they reported, and higher support levels were found to reduce depressive symptomatology regardless of risk groups. We also obtained a significant Social Support $\times$ Pregnancy Risk interaction, with significantly stronger moderating effects of received support on childbearing depressive symptomatology in the LRP group (see Fig. 3). Husband support was found to be more effective for the LRP than for the HRP group. These findings are congruent with previous reports of the buffering effects of social support on childbearing depressive mood (Campbell, Cohn, Flanagan, Popper, \& Meyers, 1992). The finding that husband support moderates depressive symptoms among low-risk pregnancies joins the literature showing the beneficial effects of close support when individuals confront moderate, daily, life stress; however, in situations of severe health stress, close support givers may 
be less effective. Studies on the effectiveness of social support during serious illness do not always confirm the social support buffering hypothesis, suggesting that, in such cases, those in close relationships (the would-be support givers) may feel less competent and find the provision of support more difficult than in normal circumstances (Coyne \& Fiske, 1992). Moreover, our data strengthen the conceptualization of high stress situations as likely to produce a deterioration of social support (Kaniasty \& Norris, 1995); according to this conceptualization, changes in social support that follow very stressful circumstances not only may not buffer but may worsen the effects of stress.

A high-risk pregnancy may promote important changes in social support networks. For instance, it has been suggested that important sources of support for HRP women might come from persons other than the spouse, such as the woman's mother (Goldstein, Diener, \& Mangelsdorf, 1996), her physician, or other healthcare professionals (Hodnett \& Osborn, 1989). Women attending the risk clinics do actually receive considerable medical support that may to some extent compensate for the need for spousal support. However, this compensation might be limited since nonintimate relationships do not seem to overcome the absence of intimate support (Coyne and DeLongis, 1986). An additional explanation of the weaker effects of received support in HRP underscores the reiterated finding that HRP women are more depressed and, consequently, are less socially competent. Hammen (1991) for instance, described depressed persons as generating more stress. In addition, subclinical levels of depression have been found to lead to significant impairment of social functioning (Beach, Martin, Blum, \& Roman, 1993).

The ineffectiveness of perceptions of received husband's support to moderate depressive symptomatology among HRP women may be also related to the husband's awareness and degree of involvement in the stressfulness of the situation. Recent contributions to social support research point to the deleterious effects of husbands' underestimations of their pregnant wives high stress levels (Chapman et al., 1997). This under- estimation has been found to exacerbate the negative effects of stressful events, contributing to a greater depressed mood (see Chapman et al.). Husbands' estimation of the stresses to which their HRP wives are subjected is an important aspect of coping processes in the childbirth period that awaits further research. Positive findings on this issue may provide important indications as to the need for greater involvement of husbands in HRP health-care processes.

Perceived support, defined as a personality characteristic rather than as an indicator of others' actual support, has been considered a main moderator of distress (B. R. Sarason et al., 1991) that correlates only modestly with measures of received support (B. R. Sarason et al., 1987). However, studies on childbearing depression provide evidence that received support may play an important role in the regulation of health and well-being wherever situational demands require the actual help of others (Collins et al., 1993; Keinan, Ezer, \& Feigin, 1992). In our sample perceptions of received support correlated moderately with anticipated support $(r=.40, p<.000)$, and had a moderating effect on depressive symptomatology, effective mainly among LRP participants. The centrality of received support in this case can be explained as related to the specific situation studied - the post-delivery period. At that time, a continuous regulation of affect and response to the demands of the new situation, and the newborn baby, may require others' actual supportive provisions (Collins et al., 1993). Under these situational characteristics, perceptions of high received support may be more effective for distress moderation than beliefs or expectations about support availability.

It is important to note that received support scores in the two groups are rather similar (refer to Table 1), excluding the possibility that HRP participants did actually find, or enroll, significantly less support. The difference between women with high- versus lowrisk pregnancies is not so much in the amount of support received, but relates to the effectiveness of the support received - that is, its moderating effect. The different effects of received support among LRP and HRP 
women can be seen as related to differences in their interpretations of the support that they get. From an interactional perspective on depression, for instance, it seems plausible that HRP women, being more depressed, receive, but do not profit from, social support. These unexpected findings may point to a vicious cycle, where depressed individuals annul the potentially beneficial effects of support by doubting, for instance, the authenticity of significant others' help or support (Joiner \& Coyne, 1999).

\section{High-risk pregnancy and working models of self and other}

Our results on the interaction between positiveself and positive-other dimensions of attachment confirm basic theoretical assumptions of attachment theory (Figure 1): Lower levels of depressive symptoms were found among participants with high positive-self and high positive-other scores-that is, participants originally classified as securely attached. Insecure attachment styles correlated with significantly higher levels of depressive symptomatology. Dismissing attachment (i.e., high positive self and low positive other scores) appears as the highest risk for depressive childbearing symptomatology. When the levels of the positive-other attachment's dimension are low, the positive-self dimension is linked to vulnerability to childbearing depression. However, high scores on the positive-other dimension moderated the vulnerability to childbearing depression.

Results revealed that LRP participants had a significantly more positive model of self than HRP women. The positive-self dimension was found to have an important main effect, beyond stress levels, on CES-D 2, corroborating existing findings on the association between negative perceptions of self and childbearing depressive symptomatology (Hopkins et al., 1984). The lower scores on the positive-self dimension among the HRP may indicate, therefore, a greater vulnerability to depressive symptoms in this sample. Because we interviewed our participants after they had been informed that their pregnancy was at high risk, we cannot overrule the possibility that this fact might have affected their positive-self scores.

The positivity of other dimension of attachment predicted a reduction of depressive symptoms in the two samples; however, it affected more significantly and effectively the depressive symptom levels of HRP participants. HRP participants who scored higher on positivity of other were significantly less depressed than their HRP partners with lower positivity of other scores. A similar, but much weaker, effect was found among LRP participants (see Figure 2). While the main effects corroborate the importance of positive models of self and of other as a resilience factor in post-delivery depression, our findings enhance the specific importance of the positive-other dimension of attachment for the study of the post-delivery mood in highly stressful pregnancies. The finding that, in the context of high health risk, the positivity of the other may have special importance for affect regulation is coherent with the main tenet of attachment theory about the internalization of an other who can be trusted as a "secure base." Accordingly, persons with more positive models of the other (secure and preoccupied participants according to Bartholomew's classification) seem to do better under more stressful conditions. These findings are congruent with the basic assumption of attachment theory that attachment assessments evaluate the learning or internalization of basic distress-soothing interactions, where the other's availability in case of need is in itself a major self-regulating mechanism. Thus, high levels of positivity of other seem to indicate a basic capacity for self-regulation that might be most effective when stress erodes close significant others' capacity for support.

These study findings imply that HRP women with insecure attachment styles, especially dismissing individuals, might be at considerable risk for childbearing depression. Knowledge about HRP patients' attachment style may thus help to identify those at risk for developing depressive symptoms. Moreover, the differences found between the effects of social support and attachment levels on HRP and LRP individuals suggest that preventive or therapeutic interventions with HRP women 
need to center not only on their present relationships, but also on the power of early relationships, and their effect on a person's beliefs, expectations, and attitudes toward others. This would imply expanding the classical cognitive models of couple therapy to include, for instance, object relational or interpersonal therapy perspectives (Anderson, Beach, \& Kaslow, 1999).

Several limitations of this study should be noted. We assessed self-reported measures only, lacking evidence in relation to the support participants actually had, or external evaluations of mothers' moods. Furthermore, the direction of the effects studied may be controversial. We based the assumed directions of the associations between social support or dimensions of attachment and depressive symptoms on a research design in which expected social support and attachment were assessed during pregnancy, and received support and depression were measured after delivery. This design does not, however, invalidate the possibility that perceptions of husband support or attachment dimensions on the one hand, and positive outcomes at a later date on the other, may stem from a common factor active during the whole process. One could assume that high social competence or

\section{References}

Ainsworth, M. D. S., Blehar, M. C., Waters, E., \& Wall, S. (1978). Patterns of attachment: A psychological study of the strange situation. Hillsdale, NJ: Erlbaum.

Anderson, P., Beach, S. R., \& H., Kaslow, N. J. (1999). Marital discord and depression: The potential of attachment theory to guide integrative clinical integration. In: T. Joiner \& J. C. Coyne (Eds.), The interactional nature of depression. (pp. 271-298). Washington, DC: American Psychological Association

Baron, R. M., \& Kenny, D. A. (1986). The moderatormediator variable distinction in social psychological research: Conceptual, strategic, and statistical considerations. Journal of Personality and Social Psychology, 51, 1173-1182.

Barrera, M. Jr. (1986). Distinctions between social support concepts, measures and models. American Journal of Community Psychology, 14, 413-445.

Bartholomew, K. (1990). Avoidance of intimacy: An attachment perspective. Journal of Social and Personal Relationships, 7, 147-178.

Bartholomew, K., \& Horowitz, L. M. (1991). Attachment styles among young adults: A test of a four-category model. Journal of Personality and Social Psychology, $61,226-244$

Beach, S. R. H., Martin, J. K., Blum, T. C., \& Roman, optimism (Carver \& Gaines, 1987) might not only explain positive perceptions of husband support and self-reports of positive attachment dimensions but also predict well-being after delivery (Cohen \& Wills, 1985). Moreover, the presence of other stressful life events may affect depressive symptom levels, and should be addressed in future studies of the relations between social support and childbearing depressive symptoms. For instance, in some cases the high risk may interfere with the pregnant women's work, which might also affect the family's economic situation. In addition, the generalizability of the present study findings to populations pertaining to different cultural and socioeconomic context remains to be proven.

Future research should dwell on long-term effects of childbearing depression on mother and infant since the severity of the deleterious effects of HRP participants' depression symptoms to themselves and their child's development might depend on the duration of the symptoms. In light of findings on boys' greater vulnerability to the long-term effects of childbearing depression (Murray, 1992; Sinclair \& Murray, 1998), infant gender should be taken into consideration in longterm studies.

P. M. (1993). Effects of marital and co-worker relationships on negative affect: Testing the central role of marriage. American Journal of Family Therapy, 21, 313-323.

Beach, S. R. H., Sandeen, E., \& O'Leary, K. D. (1990). Depression in marriage: A model for etiology and treatment. New York: Guilford Press.

Belsky, J., \& Rovine, M. (1990). Patterns of marital change across the transition to parenthood: Pregnancy to three years postpartum. Journal of Marriage and the Family, 52, 5-19.

Bolger, N., Foster, M., Vinokur, A. D., \& Ng, R. (1996). Close relationships and adjustment to a life crisis: The case of breast cancer. Journal of Personality and Social Psychology, 70, 283-294.

Bowlby, J. (1969). Attachment and loss: Attachment. New York: Basic Books.

Bowlby, J. (1973). Attachment and loss: Vol. 2, Separation. New York: Basic Books.

Bowlby, J. (1979). The making and breaking of affectional bonds. London: Tavistock.

Bowlby, J. (1980). Attachment and loss: Vol. 3, Loss, sadness and depression. New York: Basic Books.

Campbell, S. B., Cohn, J. F., Flanagan, C., Popper, S., \& Meyers, T. (1992). Course and correlates of postpartum 
depression during the transition to parenthood. Development and Psychopathology, 4, 29-47.

Carnelley, K. B., Pietromanco, P. R., \& Jaffe, K. (1994). Depression, working models of others, and relationship functioning. Journal of Personality and Social Psychology, 66, 137-140.

Carver, C. S., \& Gaines, J. G. (1987). Optimism, pessimism, and postpartum depression. Cognitive Therapy and Research, 11, 449-462.

Chapman, H. A., Hobfoll, S. E., \& Ritter, C. (1997). Partner's stress underestimation leads to women's distress: A study of pregnant inner-city women. Journal of Personality and Social Psychology, 73, 418-425.

Coffman, S., Levitt, M. J., Deets, C., \& Quigley, K. L. (1991). Close relationships in mothers of distressed and normal newborns: Support, expectancy confirmation, and maternal well being. Journal of Family Psychology, 5, 93-107.

Cohen, J., \& Cohen, P. (1983). Applied multiple regression/correlation analysis for the behavioral sciences (2nd ed.). Hillsdale, NJ: Earlbaum.

Cohen, S., \& Wills, T. A. (1985). Stress, social support, and the buffering hypothesis. Psychological Bulletin, 98, 310-357.

Collins, N. L., Dunkel-Schetter, C., Lobel, M., \& Scrimshaw, S. C. M. (1993). Social support in pregnancy: Psychosocial correlates of birth outcomes and postpartum depression. Journal of Personality and Social Psychology, 65, 1243-1258.

Coyne, J. C., \& DeLongis, A. (1986). Going beyond social support: The role of social relationships in adaptation. Journal of Consulting and Clinical Psychology, 54, 454-460.

Coyne, J. C., \& Fiske, V. (1992). Couples coping with chronic and catastrophic illness. In T. J. Akamatsu, J. H. Crowther, S. E. Hobfoll \& M. A. P. Stevens (Eds.), Family health psychology (pp. 129-149). Washington, DC: Hemisphere.

Cutrona, C. E. (1984). Social support and stress in the transition to parenthood. Journal of Abnormal Psychology, 93, 378-390.

Dunkel-Schetter, C., \& Bennett, T. I. (1990). Differentiating the cognitive and behavioral aspects of social support. In B. R. Sarason, I. G. Sarason, \& G. R. Pierce (Eds.), Social support: An interactional view (pp. 267 296). New York: Wiley.

Fleming, A. S., Ruble, D. N., Flett, G. L., \& Wagner, V. (1990). Adjustment in first-time mothers: Changes in mood and mood content during the early postpartum months. Developmental Psychology, 26, 137-143.

Goldstein, L. H., Diener, M. L., \& Mangelsdorf, S. C. (1996). Maternal characteristics and social support across the transition to motherhood: Associations with maternal behavior. Journal of Family Psychology, 10(1), 60-71.

Gotlib, I. H., Whiffen, V. E., Mount, J. H., Milne, K., \& Cordy, N. I. (1989). Prevalence rate and demographic characteristics associated with depression in pregnancy and the postpartum. Journal of Consulting and Clinical Psychology, 57, 269-274.

Gottlieb, B. H., \& Wagner, F. (1991). Stress and support processes in close relationships. In J. Eckenrode (Ed.), The social context of coping (pp. 165-188). New York: Plenum.

Griffin, D., \& Bartholomew, K. (1994). Models of self and other: Fundamental dimensions underlying measures of adult attachment. Journal of Personality and Social Psychology, 67, 430-445.
Gunster, D. C., Fusilier, M. R., \& Mayes, B. T. (1986). Role of social support in the experience of stress at work. Journal of Applied Psychology, 71.

Hammen, C. L. (1991). The generation of stress in the course of unipolar depression. Journal of Abnormal Psychology, 100, 555-561.

Harris, B. (1993). Postpartum thyroid dysfunction and postnatal depression. Annals of Medicine, 25, 215-216.

Hazan, C., \& Shaver, P. R. (1987). Romantic love conceptualized as an attachment process. Journal of Personality and Social Psychology, 52, 511-524.

Hobfoll, S. E., Nadler, A., \& Leiberman, J. (1986). Satisfaction with social support during crisis: Intimacy and self-esteem as critical determinants. Journal of Personality and Social Psychology, 51, 296-304.

Hodnett, E., \& Osborn, R. (1989). Effect of continuous intrapartum professional support on childbirth outcomes. Research Nursing Health, 12, 289-297.

Hopkins, J., Marcus, M., \& Campbell, S. B. (1984). Postpartum depression: A critical review. Psychological Bulletin, 95, 498-515.

Joiner, T., \& Coyne, J. C. (Eds.). (1999). The interactional nature of depression. Washington, DC: American Psychological Association.

Kaniasty, K., \& Norris, F. (1995). Mobilization and deterioration of social support following natural disasters. Current Directions in Psychological Science, 4, 94-98.

Keinan, G., Ezer, A., \& Feigin, M. (1992). The influence of situational and personal variables on the effectiveness of social support during childbirth. Anxiety Research, 4, 325-337.

Levitt, M. J., Coffman, S. C., Guacci-Franco, N., \& Loveless, S. C. (1994). Attachment relationships and life transitions. In M. B. Spiraling \& W. H. Berman (Eds.),Attachment in adults: Clinical and developmental perspectives (pp. 232-255). New York: Guilford Press.

Lobel, M., Dunkel-Schetter, C., \& Scrimshaw, S. C. M. (1992). Prenatal maternal stress and prematurity: A prospective study of socioeconomically disadvantaged women. Health Psychology, 11, 32-40.

Mercer, R. T., \& Ferketich, S. L. (1988). Stress and social support predictors of anxiety and depression during pregnancy. Advance in Nursing Science, 10, 26-39.

Murray, L. (1992). The impact of postnatal depression on infant development. Journal of Child Psychology and Psychiatry, 33, 543-561.

Murray, L., Fiori-Cowley, A., Hooper, R., \& Cooper, P. (1996). The impact of postnatal depression and associated adversity on early mother-infant interactions and later infant outcome. Child Development, 67, 2512-2526.

Nelson, L. J., \& Fazio, A. F. (1995). Emotional content of talk to the fetus and healthy coping behaviors during pregnancy. Infant Mental Health Journal, 16, 179-191.

Nelson, W. E. (1987). Nelson's Textbook of Pediatrics (13th ed.). Philadelphia: W.B. Saunders.

O’Hara, M. W. (1986). Social support, life events and depression during pregnancy and the puerperium. Archives of General Psychiatry, 43, 569-573.

O'Hara, M. W., Schlechte, J. A., Lewis, D. A., \& Varner, M. W. (1991). Controlled prospective study of postpartum mood disorders: Psychological, environmental and hormonal variables. Journal of Abnormal Psychology, 100, 63-73.

O’Hara, M. W., Zekoski, E. M., Phillips, L. H., \& Wright, E. J. (1990). A controlled prospective study of postpartum mood disorders: Comparing childbearing 
and non childbearing women. Journal of Abnormal Psychology, 99, 3-15.

Osofsky, J. D., \& Osofsky, H. J. (1985). Psychological and developmental perspectives on expectant and new parenthood. Review of Child Psychological Research, 8, 342-353.

O’Sullivan, J. B., \& Mahan, C. M. (1964). Criteria for the oral glucose test in pregnancy. Diabetes, 13, 278.

Peirce, R. S., Frone, M. R., Russell, M., Cooper, M. L., \& Muder, P. (2000). A longitudinal model of social contact, social support, depression and alcohol use. Health Psychology, 19, 28-38.

Priel, B., \& Besser, A. (1999). Vulnerability to postpartum depression symptomatology: Dependency, self-criticism and the moderating role of antenatal attachment. Journal of Clinical and Social Psychology, 18, 240-253.

Priel, B., \& Besser, A. (2000a). Dependency and selfcriticism among first-time mothers: The roles of global and specific support. Journal of Social and Clinical Psychology, 19, 437-450.

Priel, B., \& Besser, A. (2000b). Adult attachment styles, early relationships, antenatal attachment, and perceptions of infant temperament: A study of first-time mothers. Personal Relationships, 7, 291-310.

Priel, B., \& Besser, A. (2001). Bridging the gap between attachment and object relations theories: A study of the transition to motherhood. British Journal of Medical Psychology, 74, 85-100.

Priel, B., \& Kantor, B. (1988). The influence of high-risk pregnancies and social support systems on maternal perceptions of the infant. Infant Mental Health Journal, 9, 235-244.

Priel, B., Mitrani, D., \& Shahar, G. (1998). The social impact of attachment styles in adolescence: The transactional role of models of other. Personality and Individual Differences, 25, 1183-1197.

Priel, B., \& Shamai, D. (1995). Attachment style and perceived social support: Effects on affect regulation. Personality and Individual Differences, 19, 235-241.

Pritchard, J. A., \& MacDonald, P. C. (1980). Williams obstetrics. New York: Appleton Century Crofts.

Radloff, L. (1977). The CES-D Scale: A self-report depression scale for research in the general population. Applied Psychosocial Measurement, 1, 385-401.

Rini, C. K., Dunkel-Schetter, C., Wadhwa, P. D., \& Sandman, C. A. (1999). Psychological adaptation and birth outcomes: The role of personal resources, stress, and sociocultural context in pregnancy. Health Psychology, 18, 333-345.
Sarason, B. R., Pierce, G. R., Shearin, E. N., Sarason, I. G., Waltz, J. A., \& Poppe, L. (1991). Perceived social support and working models of self and actual others. Journal of Personality and Social Psychology, 60, 273-287.

Sarason, B. R., Sarason, I. G., \& Pierce, G. R. (Eds.). (1990). Social support: An interactional view. New York: Wiley.

Sarason, B. R., Shearin, E. N., Pierce, G. R., \& Sarason, I. G. (1987). Interrelations of social support measures: Theoretical and practical implications. Journal of Personality and Social Psychology, 52, 813-832.

Sarason, I. G., Pierce, G. R., \& Sarason, B. R. (1990). Social support and interactional processes: A triadic hypothesis. Journal of Social and Personal Relationships, 7, 495-506.

Sarason, I. G., Sarason, B. R., \& Shearin, E. (1986). Social support as an individual difference variable: Its stability, origins and relational aspects. Journal of Personality and Social Psychology, 50, 845-855.

Simpson, J. A., Rholes, W. S., \& Nelligan, J. S. (1992). Support seeking and support giving within couples in an anxiety-provoking situation: The role of attachment styles. Journal of Personality and Social Psychology, 62, 434-444.

Sinclair, D., \& Murray, L. (1998). Effects of postnatal depression on children's adjustment in school. British Journal of Psychiatry, 172, 58-63.

Terry, D. J., Mayocchi, L., \& Hynes, G. (1996). Depressive symptomatology in new mothers: A stress and coping perspective. Journal of Abnormal Psychology, 105, 220-231.

Wallace, J. L., \& Vaux, A. (1993). Social support network orientation: The role of adult attachment style. Journal of Social and Clinical Psychology, 12, 354-365.

Whiffen, V. E. (1988). Vulnerability to postpartum depression: A prospective multivariate study. Journal of Abnormal Psychology, 97, 467-474.

Whiffen, V. E. (1992). Is postpartum depression a distinct diagnosis? Clinical Psychology Review, 12, 485-508.

Whiffen, V. E., \& Gotlib, I. H. (1993). Comparison of postpartum and non postpartum depression: Clinical presentation, psychiatric history and psychosocial functioning. Journal of Consulting and Clinical Psychology, 61, 485-494.

Wills, T. A. (1985). Supportive functions of interpersonal relationships. In S. Cohen \& S. L. Smith (Eds.), Social support and health (pp. 61-82). Orlando, FL: Academic Press. 